\title{
NSW Annual Report Describing Adverse Events Following Immunisation, 2010
}

\author{
Deepika Mahajan ${ }^{\mathrm{A}, \mathrm{D}}$, Sue Campbell-Lloyd ${ }^{\mathrm{B}}$, \\ Jane Cook ${ }^{\mathrm{C}}$ and Robert I. Menzies ${ }^{\mathrm{A}}$ \\ ${ }^{\mathrm{A}}$ National Centre for Immunisation Research and Surveillance, \\ The Children's Hospital at Westmead \\ ${ }^{\mathrm{B}}$ AIDS and Infectious Diseases Branch, NSW Department of Health \\ ${ }^{\mathrm{C}}$ Office of Medicine Safety Monitoring, Therapeutic Goods \\ Administration \\ ${ }^{\mathrm{D} C o r r e s p o n d i n g}$ author. Email: DeepikM2@chw.edu.au
}

\begin{abstract}
Aim: This report summarises Australian passive surveillance data for adverse events following immunisation in NSW for 2010. Methods: Analysis of de-identified information on all adverse events following immunisation reported to the Therapeutic Goods Administration. Results: 424 adverse events following immunisation were reported for vaccines administered in 2010; this is $6 \%$ lower than 2009 but $24 \%$ higher than 2008 and the second highest number since 2003. A total of $274(65 \%)$ adverse events involved seasonal or pandemic influenza vaccines. Reports were predominantly of mild transient events: the most commonly reported reactions were fever, allergic reaction, injection site reaction, malaise and headache. Only $9 \%$ of the reported adverse events were serious in nature, including eight reports of febrile convulsions in children following seasonal influenza vaccine. Conclusion: The large number of reports in 2010 is attributable to the high rates of fever and febrile convulsions in children after vaccination with 2010 seasonal trivalent influenza vaccine, as well as pandemic (H1N1) 2009 influenza vaccine.
\end{abstract}

Adverse events following immunisation are generally regarded as any serious or unexpected adverse events that occur after the administration of a vaccine(s). They may be caused by a vaccine(s) or may be coincidental. Adverse events may also include conditions that occur following the incorrect handling and/or administration of a vaccine(s). Post-licensure surveillance - the practice of monitoring the safety of a vaccine after it has been licensed and released in the market - is important to detect rare, late onset and unexpected events which are difficult to detect in pre-licensure vaccine trials.

This is the second annual report for adverse events following immunisation in New South Wales (NSW). It summarises passive surveillance data reported from NSW in 2010 and describes reporting trends over the 11-year period 2000-2010. To assist readers, a glossary of the abbreviations of the vaccines referred to in this report is provided in Box 1.

Trends in reported adverse events following immunisation are influenced by changes to vaccines provided through the National Immunisation Program. Changes in previous years have been reported elsewhere. ${ }^{1-12}$ Two recent changes to vaccine funding and availability influenced the adverse events surveillance data presented in this report:

(i) For the first time, in 2010 annual vaccination with seasonal trivalent influenza vaccine (containing three influenza strains A/H1N1, A/H3N2 and B) was funded under the National Immunisation Program for people aged 6 months and over with medical risk factors (previously subsidised Pharmaceutical Benefits Scheme) and for all Aboriginal people aged 15 years and over (previously all Aboriginal adults aged 50 years and over and 15-49 years with medical risk factors). ${ }^{13}$

(ii) Pandemic H1N1 (pH1N1) influenza vaccine (Panvax ${ }^{\circledR}$ ) was introduced in Australia from 30 September 2009 for people aged 10 years and over, and from December 2009 for children aged 6 months to 10 years. ${ }^{14}$

\section{Methods}

Adverse events following immunisation are notifiable to public health units by medical practitioners and hospital CEOs under the NSW Public Health Act 1991. Cases with outstanding information and all serious adverse events are followed up by public health units and NSW Health, and all notifications are forwarded to the Therapeutic Goods Administration. The Therapeutic Goods Administration also receives reports directly from vaccine manufacturers, members of the public and other sources. ${ }^{15,16}$ During the $\mathrm{pH} 1 \mathrm{~N} 1$ vaccine program, reports of adverse events following the administration of this vaccine were required to be notified directly to the 
Box 1. List of abbreviations of vaccine types used in this report

\begin{tabular}{|ll|}
\hline BCG & Bacillus of Calmette and Guérin (i.e. tuberculosis bacillus) \\
dT & diphtheria-tetanus, adolescent and adult formulation \\
DTPa & diphtheria-tetanus-pertussis (acellular), paediatric formulation \\
dTpa & diphtheria-tetanus-pertussis (acellular), adolescent and adult formulation \\
dTpa-IPV & combined dTpa and inactivated poliovirus \\
DTPa-HepB & combined diphtheria-tetanus-pertussis (acellular) and hepatitis B \\
DTPa-IPV & combined diphtheria-tetanus-pertussis (acellular) and inactivated poliovirus (quadrivalent) \\
DTPa-IPV-HepB & combined diphtheria-tetanus-pertussis (acellular), inactivated poliovirus and hepatitis B (pentavalent) \\
DTPa-IPV-HepB-Hib & combined diphtheria-tetanus-pertussis (acellular), inactivated poliovirus, hepatitis B and \\
& Haemophilus influenzae type b vaccine (hexavalent) \\
HepB & hepatitis B \\
Hib & Haemophilus influenzae type b \\
Hib-HepB & combined Haemophilus influenzae type b and hepatitis B \\
HPV & human papillomavirus \\
IPV & inactivated poliovirus vaccine \\
Men4PV & meningococcal polysaccharide tetravalent vaccine \\
MenCCV & meningococcal C conjugate vaccine \\
MMR & measles-mumps-rubella \\
7vPCV & 7-valent pneumococcal conjugate vaccine \\
23vPPV & 23-valent pneumococcal polysaccharide vaccine \\
\end{tabular}

Therapeutic Goods Administration rather than to a public health unit and reporting by the general public to the Therapeutic Goods Administration was actively promoted. All reports are assessed by the Therapeutic Goods Administration (TGA) using internationally-consistent criteria $^{17}$ and entered into the Australian Adverse Drug Reactions System database.

\section{Adverse events following immunisation data}

De-identified information on adverse events following immunisation (AEFI) reports from the Australian Adverse Drug Reactions System database was released to the National Centre for Immunisation Research and Surveillance for analysis and reporting. AEFI records contained in the Australian Adverse Drug Reactions System database were eligible for inclusion in the analysis if: a vaccine was recorded as 'suspected' of involvement in the reported adverse event; the vaccination occurred between 1 January 2000 and 31 December 2010; and the residential address of the individual was recorded as NSW. If the vaccination date was not recorded the date of onset of symptoms or signs was taken as the date of vaccination.

The term 'AEFI record' is used throughout this report because a single adverse event notification to the TGA can generate more than one record in the Australian Adverse Drug Reactions System database. This may occur if there is a time sequence of separate adverse reactions in a single patient.

AEFI records are classified as 'suspected' by the TGA. An AEFI record is classified as 'not suspected' and excluded from the Adverse Drug Reactions System database if: there is no reasonable temporal association between the use of a drug and the clinical event (generally defined as onset of symptoms within 28 days following vaccination); the record does not contain enough information for an adequate assessment or the information is contradictory; or if a clinical event is explained as likely to have arisen from other causes.

\section{Study definitions of AEFI outcomes and reactions}

AEFIs were defined as 'serious' or 'non-serious' based on information recorded in the Australian Adverse Drug Reactions System database and using criteria similar to those used elsewhere. ${ }^{17,18}$ In this report, an AEFI is defined as 'serious' if the record indicated that the person had recovered with sequelae, been admitted to a hospital, experienced a life-threatening event, or died.

Because children generally receive several vaccines at the same time, all administered vaccines are usually listed as 'suspected' of involvement in a systemic adverse event as it is usually not possible to attribute the event to a single vaccine.

Typically, each AEFI record listed several symptoms, signs and diagnoses that had been re-coded by TGA staff from the description provided by the reporter into standardised terms using the Medical Dictionary for Regulatory Activities (MedDRA ${ }^{\circledR}$ ). ${ }^{19}$ AEFI reports of suspected anaphylaxis and hypotonic-hyporesponsive episodes were classified by the TGA using the Brighton Collaboration case definitions. $^{20,21}$ 


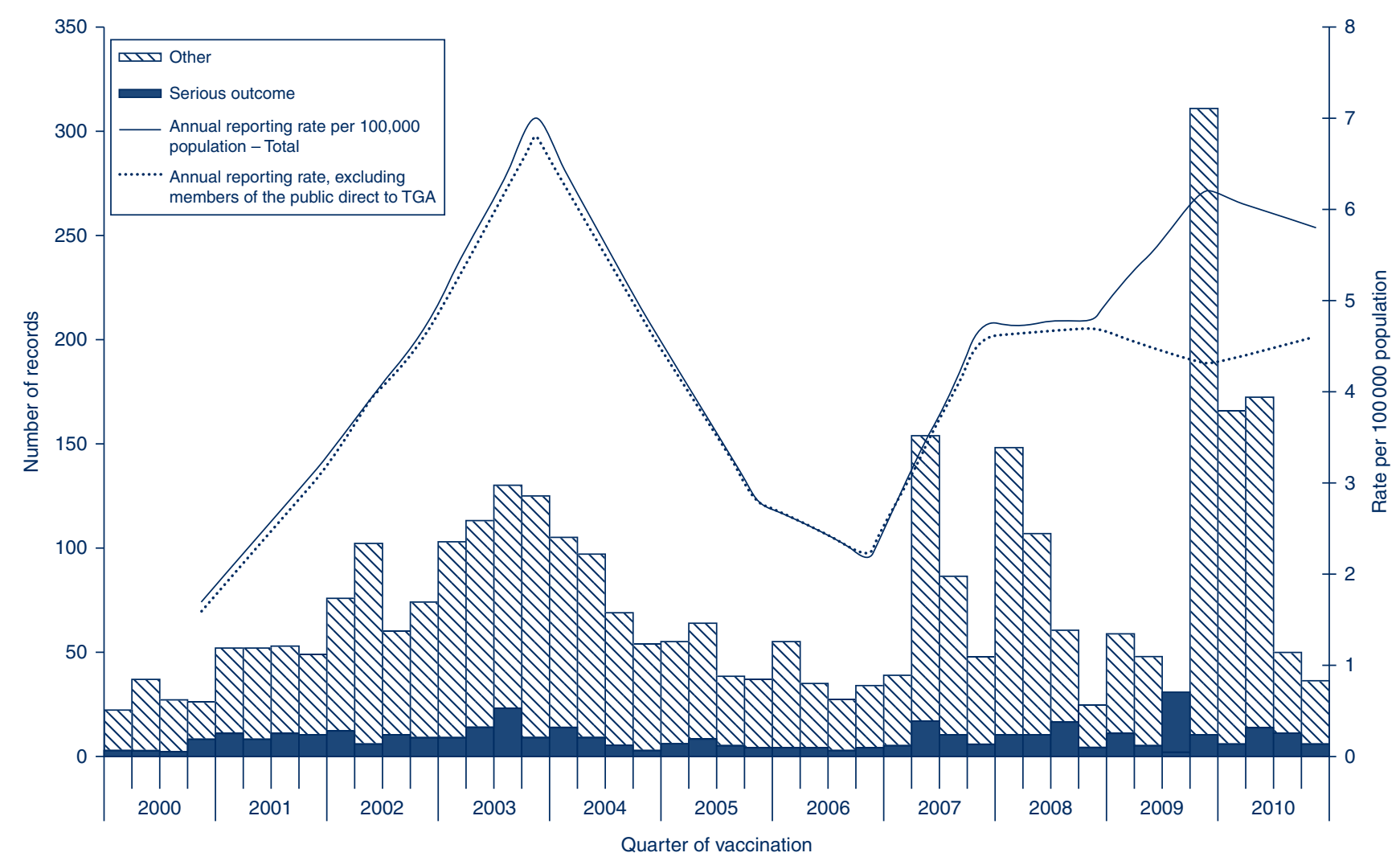

Figure 1. Reports of adverse events following immunisation, NSW, 2000-2010, by quarter of vaccination.

Adverse events following immunisation are generally regarded as any serious or unexpected adverse events that occur after the administration of a vaccine(s).

For reports where the date of vaccination was not recorded, the date of onset was used as a proxy for the vaccination date.

Source: Adverse Drug Reactions System database, Therapeutic Goods Administration.

\section{Data analysis}

All data analyses were performed using SAS (version 9.1.3, SAS Institute, Cary, NC, USA). Average annual population-based reporting rates were calculated using population estimates obtained from the Australian Bureau of Statistics. ${ }^{22}$

AEFI reporting rates per 100000 administered doses were estimated where information on dose numbers was available from: the Australian Childhood Immunisation Register for National Immunisation Program vaccines for children aged less than 7 years; NSW Health data on vaccines administered in schools for 12-17-year-olds; and the 2009 NSW Population Health Survey for influenza vaccines and the 23 -valent pneumococcal polysaccharide vaccine (23vPPV) for adults aged 65 years and over. ${ }^{23}$ For the $23 \mathrm{vPPV}$ vaccine, as a single booster is recommended 5 years after the first dose, the number of respondents who declared being vaccinated within 5 years was divided by five to get an estimate of the average number of doses for a single year.

\section{Notes on interpretation}

The data reported here are provisional only, particularly for the fourth quarter of 2010, because of reporting delays and the late onset of some AEFIs. The information collated in the Australian Adverse Drug Reactions System database is intended primarily to detect signals of adverse events and to inform hypothesis generation. While AEFI reporting rates can be estimated using appropriate denominators, they cannot be interpreted as incidence rates due to under-reporting and biased reporting of suspected events, and the variable quality and completeness of information provided in individual notification reports. ${ }^{1-12,23}$

It is important to note that this annual report is based on vaccine and reaction term information collated in the Australian Adverse Drug Reactions System database and not on comprehensive clinical notes. Individual records in the database list symptoms, signs and diagnoses that were used to define a set of reaction categories based on the case definitions provided in the 9th edition of The Australian Immunisation Handbook. ${ }^{16}$ These reaction categories are similar, but not identical, to the AEFI case definitions.

The reported symptoms, signs and diagnoses in each AEFI record in the Australian Adverse Drug Reactions System database are temporally associated with vaccination but are not necessarily causally associated with one or more vaccines. 


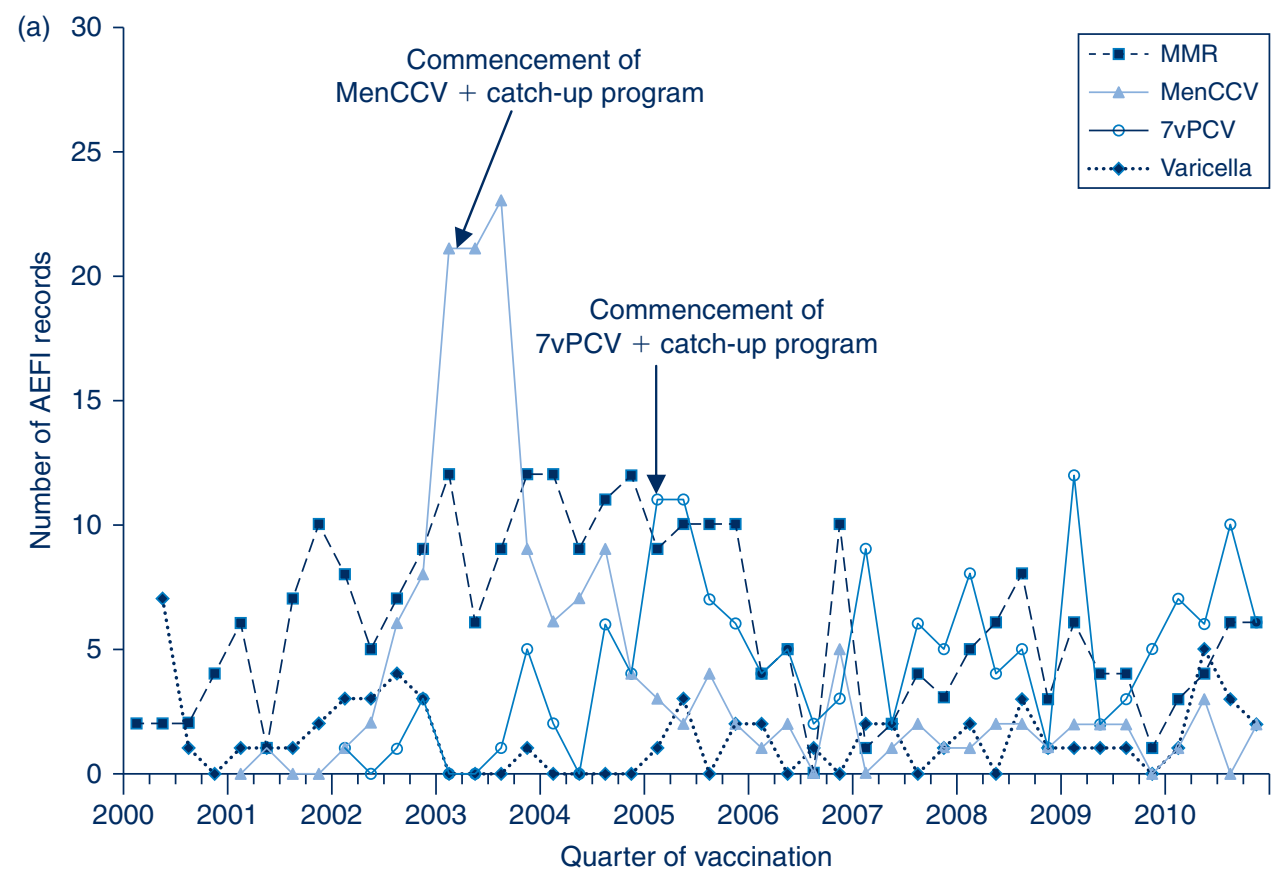

Figure 2a. Adverse events following immunisation for children aged $<7$ years in frequently suspected vaccines (including MMR, MenCCV, 7vPCV and varicella), NSW, 2000-2010, by quarter of vaccination.

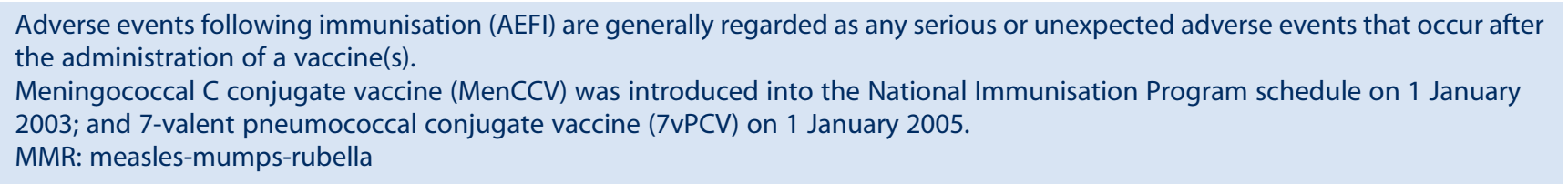

Source: Adverse Drug Reactions System database, Therapeutic Goods Administration.

\section{Results}

There was a total of 424 AEFI records for NSW in the Australian Adverse Drug Reactions System database with a date of vaccination (or onset of an adverse event if vaccination date was not reported) in 2010. This was a $6 \%$ decrease on the 450 records in 2009 and a $24 \%$ increase on the 340 records in 2008. Eighty percent $(n=338)$ of the AEFI records during 2010 were reported in the first two quarters of the year, a substantial increase (68\%) from the corresponding period in 2009 (24\%, $n=107)$. Fifty-seven percent $(n=243)$ were for children aged less than 7 years. Thirty-six percent $(n=154)$ were reported to the TGA by NSW Health and the remainder were reported directly to the TGA; $21 \%(n=88)$ by members of the public, $38 \%(n=161)$ by doctors/other health care providers, and $5 \%(n=21)$ by hospitals. The number of AEFI reports by members of the public was much greater in 2009 and 2010 than in $2008(2 \%, n=7)$ with $95 \%$ of reports by members of the public relating to seasonal influenza and $\mathrm{pH} 1 \mathrm{~N} 1$ influenza vaccines.

\section{Reporting trends}

The AEFI reporting rate for 2010 was 5.8 per 100000 population, compared with 6.2 per 100000 population in 2009 (Figure 1). This is the third highest reporting rate for the period 2000-2010, after the first peak in 2003 that coincided with the national program for meningococcal $\mathrm{C}$ conjugate vaccine and high rates of reporting from the 18-month dose of DTPa; and the second peak in 2009 following the commencement of the $\mathrm{pH} 1 \mathrm{~N} 1$ program (Figure 1). Figure 1 shows the increase in reporting by the general public directly to the TGA in 2009 and 2010, and that the majority of reported events (from all reporter types) were of a non-serious nature. Figures $2 b$ and 3 show that the rise in the reporting rate in 2009 and 2010 was due to reports following receipt of $\mathrm{pH} 1 \mathrm{~N} 1$ vaccine and seasonal influenza vaccines, and that in 2010 this was predominantly in children. Figures 2 and 3 also demonstrate marked variations of reporting levels in association with previous changes to the National Immunisation Program from 2000 onwards.

The usual seasonal pattern of AEFI reporting from older Australians receiving $23 \mathrm{vPPV}$ and influenza vaccines during the autumn months (March-June) is evident in Figure 3, with a higher reporting rate for influenza in 2010.

\section{Age distribution}

In 2010, the highest population-based AEFI reporting rate occurred in infants aged less than 1 year, the age group that received the highest number of vaccines (Figure 4). Compared with 2009, there was a four-fold increase in AEFI 


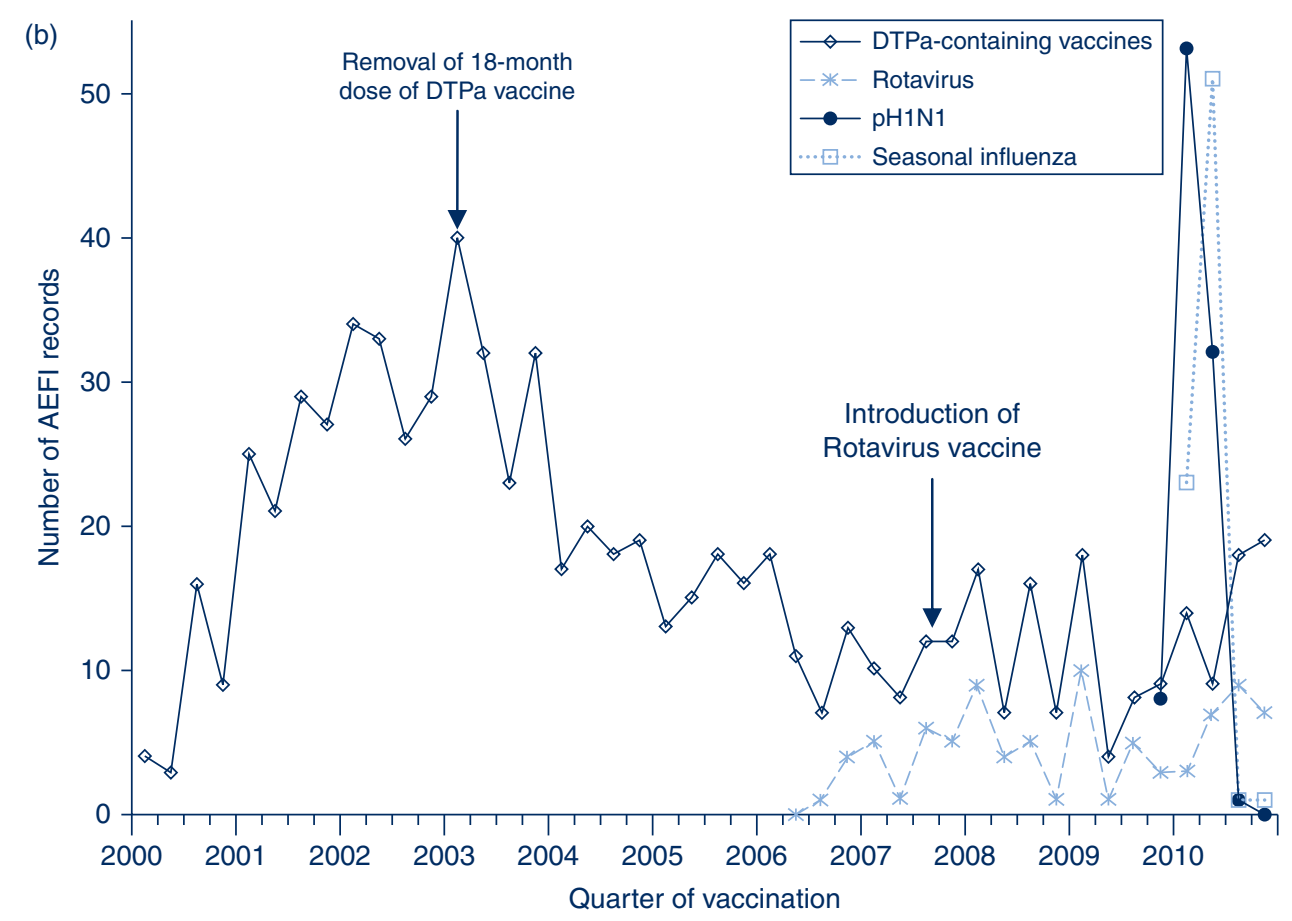

Figure 2b. Adverse events following immunisation for children aged $<7$ years in frequently suspected vaccines (including DTPa-containing vaccines, seasonal influenza, pH1N1 and rotavirus), NSW, 2000-2010, by quarter of vaccination.

Adverse events following immunisation are (AEFI) generally regarded as any serious or unexpected adverse events that occur after the administration of a vaccine(s).

DTPa-IPV and DTPa-IPV-HepB-Hib (hexavalent) vaccines in November 2005; rotavirus (RotaTeq ${ }^{\circledR}$ and Rotarix ${ }^{\circledR}$ ) vaccines 1 July 2007 ; pH1N1 influenza vaccine was introduced in September 2009; and seasonal influenza vaccine in 2010.

DTPa: diphtheria-tetanus-pertussis (acellular), paediatric formulation

pH1N1: pandemic (H1N1) 2009 influenza

Source: Adverse Drug Reactions System database, Therapeutic Goods Administration.

reporting rates among children aged 7 years and under (9.9 to 37.9 per 100000 population), related to the increase in reports following the administration of seasonal and pH1N1 influenza vaccines. There were also increases in the reporting rates of most other individual vaccines given to this age group in 2010 (Table 1) compared to $2009 .{ }^{24} \mathrm{In}$ adults there were also substantial increases in the number of reports following seasonal influenza vaccines, but about a three-fold decrease in AEFI reporting rates in this age group overall (6.3 to 2.4 per 100000 population), due to the decline in reports following pH1N1 influenza vaccine in this age group.

\section{Vaccines}

Of the 424 records, 150 (35\%) included receipt of seasonal influenza vaccine and 126 records (30\%) included pH1N1 influenza vaccine. Vaccines containing diphtheria, tetanus and acellular pertussis antigens were reported in 80 records (19\%), with dTpa (20 records, 4.7\%) and hexavalent DTPa-IPV-HepB-Hib (28 records, 6.6\%) being the most frequently reported among DTPa-containing vaccines. The other frequently reported vaccines were $23 \mathrm{vPPV}$ (30 records, 7\%), 7vPCV (29 records, 7\%) and rotavirus (26 records, 6\%) (Table 1). Of vaccines with reliable data on doses administered, those with the highest AEFI rates per 100000 doses were DTP-IPV (33.0), 23vPPV (23.4), rotavirus (15.4) and HPV (15.2). Few AEFIs $(n=24)$ occurred following the co-administration of influenza and non-influenza vaccines $(14 \%$ of 174 reports of non-influenza vaccines).

\section{Reactions}

The distribution and frequency of reactions listed in AEFI records for 2010 are shown in Table 2 . The most frequently reported adverse events were fever $(49 \%)$, allergic reaction $(31 \%)$, injection site reaction (19\%), malaise $(16 \%)$, headache $(12 \%)$, myalgia $(9 \%)$, rash $(8 \%)$ and nausea $(7 \%)$ (Table 2).

\section{Severity of outcomes}

Nine percent $(n=37)$ of events were defined as 'serious' (i.e. recovery with sequelae, requiring hospitalisation, experiencing a life-threatening event or death); higher than observed in 2009. Numbers of reported events and events with outcomes defined as 'serious' are shown in Table 1.

Fifteen percent of records were recorded as 'not fully recovered' at the time of reporting (Table 3); 59\% of these were following receipt of $\mathrm{pH} 1 \mathrm{~N} 1$ and seasonal influenza 


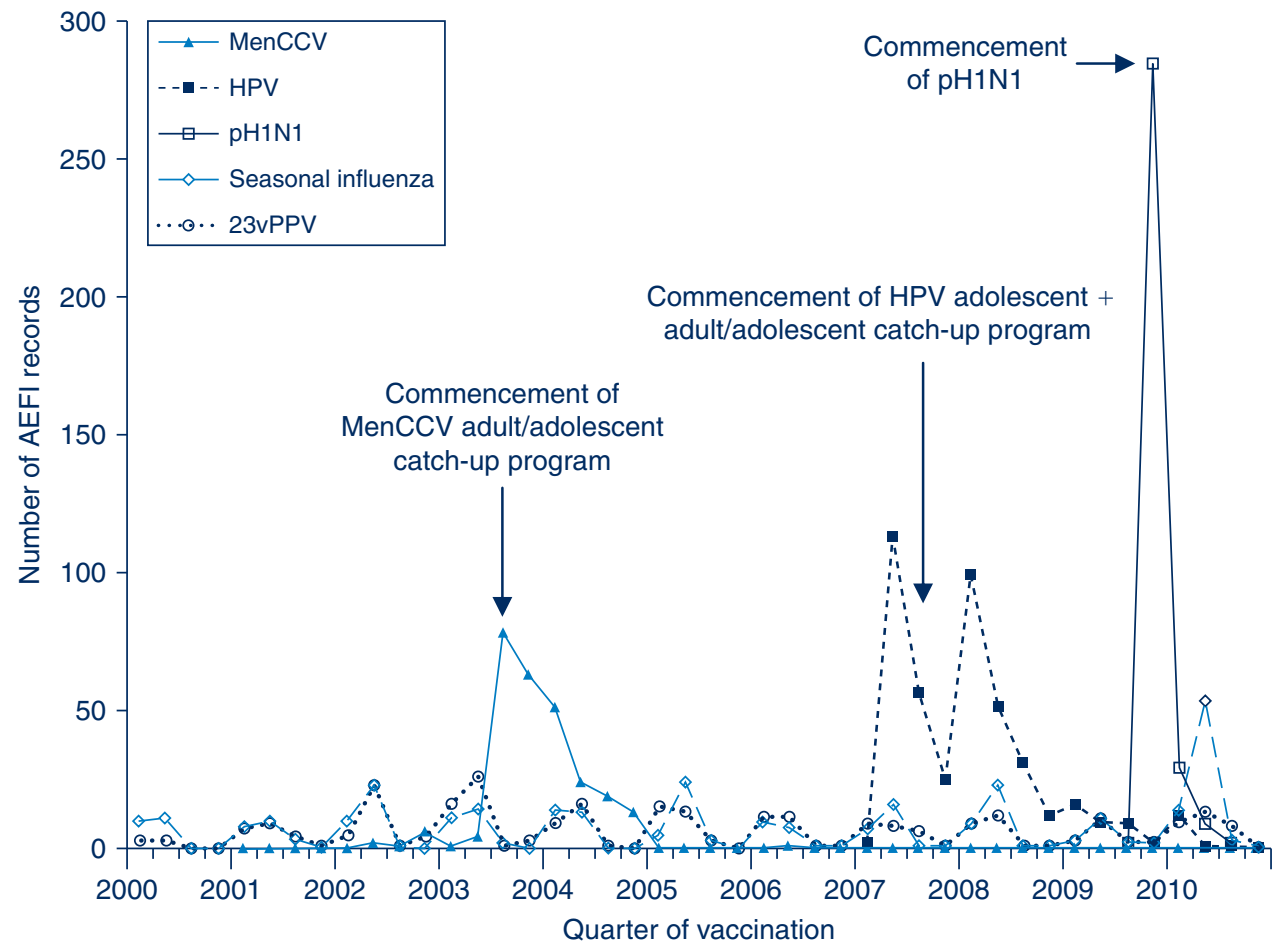

Figure 3. Adverse events following immunisation for children aged $>7$ years in frequently suspected vaccines (including MenCCV, seasonal influenza, 23vPPV, HPV and pH1N1), NSW, 2000-2010, by quarter of vaccination.

Adverse events following immunisation (AEFI) are generally regarded as any serious or unexpected adverse events that occur after the administration of a vaccine(s).

23vPPV: 23-valent pneumococcal polysaccharide vaccine

MenCCV: meningococcal C conjugate vaccine

HPV: human papillomavirus

pH1N1: pandemic (H1N1) 2009 influenza

Source: Adverse Drug Reactions System database, Therapeutic Goods Administration.

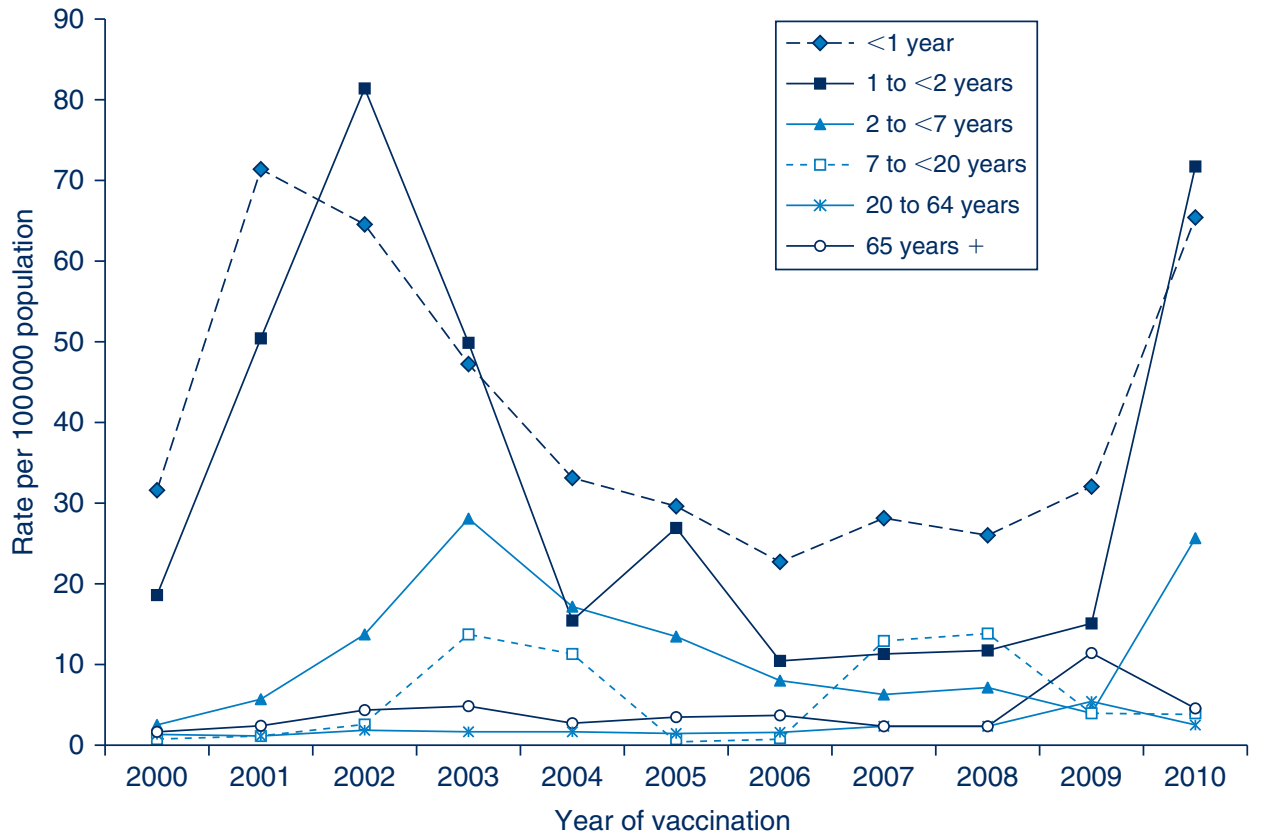

Figure 4. Reporting rates of adverse events following immunisation for NSW per 100000 population, 2000-2010, for six age groups and by year of vaccination.

Adverse events following immunisation (AEFI) are generally regarded as any serious or unexpected adverse events that occur after the administration of a vaccine(s).

Source: Adverse Drug Reactions System database, Therapeutic Goods Administration. 
Table 1. Vaccine types listed as 'suspected' in records of adverse events following immunisation for four age groups $(<7,12-17,18-64$ and $\geq 65$ years), NSW, 2010

\begin{tabular}{|c|c|c|c|c|}
\hline \multirow[t]{2}{*}{ Vaccines $^{a}$} & AEFI records ${ }^{b}$ & 'Serious' outcome & Vaccine doses $^{d}$ & $\begin{array}{l}\text { Reporting rate per } 100000 \text { doses }^{\mathrm{e}} \\
\qquad(95 \% \mathrm{Cl})\end{array}$ \\
\hline & $n$ & $n$ & $n$ & 2010 \\
\hline \multicolumn{5}{|l|}{$<7$ years } \\
\hline DTPa-IPV & 32 & 2 & 90999 & $35.2(24.1-49.7)$ \\
\hline Hexavalent (DTPa-IPV-HepB-Hib) & 28 & 9 & 268847 & $10.4(6.9-15.1)$ \\
\hline Haemophilus influenzae type b & 6 & 0 & 90863 & $6.6(2.4-14.4)$ \\
\hline Measles-mumps-rubella & 19 & 2 & 183385 & $10.4(6.2-16.2)$ \\
\hline Rotavirus & 26 & 10 & 168669 & $15.4(10.1-22.6)$ \\
\hline $7 \mathrm{vPCV}$ & 29 & 9 & 269682 & $10.8(7.2-15.4)$ \\
\hline Varicella & 11 & 3 & 88131 & $12.5(6.2-22.4)$ \\
\hline MenCCV & 6 & 0 & 93689 & $6.4(2.3-14.0)$ \\
\hline pH1N1 & 86 & 9 & $\mathrm{n} / \mathrm{a}$ & $\mathrm{n} / \mathrm{a}$ \\
\hline Seasonal influenza & 76 & 3 & $\mathrm{n} / \mathrm{a}$ & $\mathrm{n} / \mathrm{a}$ \\
\hline \multicolumn{5}{|l|}{$12-17$ years } \\
\hline HPV & 13 & 0 & 92305 & $14.1(7.5-24.1)$ \\
\hline dTpa & 5 & 0 & 117646 & $4.3(1.4-9.9)$ \\
\hline Hepatitis B & 12 & 0 & 104208 & $11.5(15.9-20.1)$ \\
\hline Varicella & 2 & 0 & 27775 & $7.2(0.7-25.9)$ \\
\hline pH1N1 & 2 & 0 & $\mathrm{n} / \mathrm{a}$ & $\mathrm{n} / \mathrm{a}$ \\
\hline Seasonal influenza & 1 & 0 & $\mathrm{n} / \mathrm{a}$ & $n / a$ \\
\hline \multicolumn{5}{|l|}{$18-64$ years } \\
\hline Seasonal influenza & 38 & 0 & $\mathrm{n} / \mathrm{a}$ & $\mathrm{n} / \mathrm{a}$ \\
\hline pH1N1 & 27 & 0 & $\mathrm{n} / \mathrm{a}$ & $\mathrm{n} / \mathrm{a}$ \\
\hline dTpa & 13 & 1 & $\mathrm{n} / \mathrm{a}$ & $\mathrm{n} / \mathrm{a}$ \\
\hline 23vPPV & 4 & 0 & $\mathrm{n} / \mathrm{a}$ & $\mathrm{n} / \mathrm{a}$ \\
\hline \multicolumn{5}{|l|}{$\geq 65$ years } \\
\hline Influenza & 24 & 7 & 718863 & $3.3(2.1-5.0)$ \\
\hline 23vPPV & 26 & 2 & 110899 & $23.4(15.3-34.4)$ \\
\hline dTpa & 2 & 0 & $\mathrm{n} / \mathrm{a}$ & $\mathrm{n} / \mathrm{a}$ \\
\hline $\mathrm{pH} 1 \mathrm{~N} 1$ & 1 & 0 & $\mathrm{n} / \mathrm{a}$ & $\mathrm{n} / \mathrm{a}$ \\
\hline \multicolumn{5}{|l|}{ Age group (years) } \\
\hline$<1$ year $^{\mathrm{f}}$ & 41 & 12 & 725631 & $5.7(4.1-7.7)$ \\
\hline 1 to $<2$ years $^{f}$ & 18 & 4 & 331208 & $5.4(3.2-8.6)$ \\
\hline 2 to $<7$ years $^{f}$ & 32 & 2 & 197426 & $16.2(11.1-22.9)$ \\
\hline $12-17$ years $^{f}$ & 23 & 0 & 341934 & $6.7(4.3-10.1)^{9}$ \\
\hline $18-64$ years & 88 & 1 & $\mathrm{n} / \mathrm{a}$ & $\mathrm{n} / \mathrm{a}$ \\
\hline $65+$ years & 43 & 7 & 829762 & $5.2(3.7-7.0)^{\mathrm{h}}$ \\
\hline
\end{tabular}

Adverse events following immunisation (AEFI) are generally regarded as any serious or unexpected adverse events that occur after the administration of a vaccine(s).

dTpa: diphtheria-tetanus-pertussis (acellular), adolescent and adult formulation

DTPa-IPV: combined dTpa and inactivated poliovirus

DTPa-IPV-HepB-Hib: combined diphtheria-tetanus-pertussis (acellular), inactivated poliovirus, hepatitis B and Haemophilus influenzae type $b$ vaccine (hexavalent)

MenCCV: meningococcal C conjugate vaccine

pH1N1: pandemic (H1N1) 2009 influenza

7vPCV: 7-valent pneumococcal conjugate vaccine

23vPPV: 23-valent pneumococcal polysaccharide vaccine

${ }^{a}$ Records where at least one of the vaccines shown in the table was suspected of involvement in the reported adverse event. A 'serious' outcome is defined as recovery with sequelae, hospitalisation, life-threatening event or death. ${ }^{17}$

${ }^{b}$ Number of AEFI records in which the vaccine was coded as 'suspected' of involvement in the reported adverse event and the vaccination was administered between 1 January and 31 December 2010. More than one vaccine may be coded as 'suspected' if several were administered at the same time.

'Serious' outcomes are defined in the Methods section.

'Number of vaccine doses recorded and administered between 1 January and 31 December 2010.

'The estimated AEFI reporting rate per 100000 vaccine doses recorded.

fNumber of AEFI records excluding influenza vaccines administered alone. Most reports include more than one vaccine.

${ }^{9}$ School-based only.

${ }^{h}$ Seasonal influenza and 23vPPV only.

Source: Adverse Drug Reactions System database, Therapeutic Goods Administration. 
Table 2. Reaction categories of interest mentioned in records of adverse events following immunisation for two age groups ( $<7$ and $\geq 7$ years), NSW, 2010

\begin{tabular}{|c|c|c|c|c|c|c|c|c|c|}
\hline \multirow[t]{3}{*}{ Reaction category ${ }^{a, b, c}$} & \multirow{3}{*}{$\begin{array}{c}\text { AEFI records } \\
n\end{array}$} & \multirow{2}{*}{\multicolumn{2}{|c|}{$\begin{array}{l}\text { 'Serious' } \\
\text { outcome }^{d}\end{array}$}} & \multirow{2}{*}{\multicolumn{2}{|c|}{$\begin{array}{l}\text { Only reaction } \\
\text { reported }^{\mathrm{e}}\end{array}$}} & \multicolumn{4}{|c|}{ Age group $^{d}$} \\
\hline & & & & & & \multicolumn{2}{|c|}{$<7$ years } & \multicolumn{2}{|c|}{$\geq 7$ years } \\
\hline & & $n$ & $\%$ & $n$ & $\%$ & $n$ & $\%$ & $n$ & $\%$ \\
\hline Fever & 211 & 6 & 3 & 18 & 9 & 58 & 75 & 50 & 24 \\
\hline Allergic reaction ${ }^{f}$ & 131 & 5 & 4 & 10 & 8 & 91 & 69 & 36 & 27 \\
\hline Injection site reaction & 82 & 3 & 4 & 17 & 21 & 29 & 35 & 52 & 64 \\
\hline Rash $^{g}$ & 36 & 2 & 6 & 11 & 31 & 24 & 67 & 12 & 33 \\
\hline Convulsions & 29 & 9 & 31 & 12 & 41 & 27 & 93 & 2 & 7 \\
\hline Abnormal crying & 20 & 3 & 15 & 1 & 5 & 20 & 100 & 0 & 0 \\
\hline Arthralgia & 13 & 0 & 0 & 0 & 0 & 1 & 8 & 12 & 92 \\
\hline Somnolence & 10 & 1 & 10 & 0 & 0 & 8 & 80 & 2 & 20 \\
\hline Hypotonic-hyporesponsive episode & 8 & 6 & 75 & 4 & 50 & 8 & 100 & 0 & 0 \\
\hline Lymphadenopathy/itis $^{\text {h }}$ & 8 & 0 & 0 & 0 & 0 & 0 & 0 & 8 & 100 \\
\hline Arthritis & 6 & 1 & 17 & 3 & 50 & 1 & 17 & 5 & 83 \\
\hline Guillain-Barrè syndrome & 4 & 3 & 75 & 4 & 100 & 0 & 0 & 4 & 100 \\
\hline Syncope & 4 & 0 & 0 & 1 & 25 & 1 & 25 & 3 & 75 \\
\hline Anaphylactic reaction & 1 & 1 & 100 & 1 & 100 & 0 & 0 & 1 & 100 \\
\hline Idiopathic Thrombocytopenic Purpura & 1 & 1 & 100 & 1 & 100 & 1 & 100 & 0 & 0 \\
\hline Malaise & 66 & 1 & 2 & 0 & 0 & 36 & 55 & 29 & 44 \\
\hline Headache & 49 & 0 & 0 & 2 & 4 & 15 & 31 & 34 & 69 \\
\hline Myalgia & 39 & 2 & 5 & 0 & 0 & 9 & 23 & 30 & 77 \\
\hline Nausea & 30 & 0 & 0 & 0 & 0 & 3 & 10 & 27 & 90 \\
\hline Abdominal pain & 21 & 2 & 10 & 0 & 0 & 12 & 57 & 8 & 38 \\
\hline Pain & 21 & 0 & 0 & 0 & 0 & 6 & 29 & 15 & 71 \\
\hline Dizziness & 15 & 0 & 0 & 0 & 0 & 0 & 0 & 15 & 100 \\
\hline Erythema & 9 & 0 & 0 & 0 & 0 & 7 & 78 & 2 & 22 \\
\hline Respiratory rate/rhythm change & 8 & 1 & 13 & 0 & 0 & 8 & 100 & 0 & 0 \\
\hline Reduced sensation & 4 & 0 & 0 & 2 & 50 & 0 & 0 & 3 & 75 \\
\hline Weakness & 3 & 0 & 0 & 0 & 0 & 1 & 33 & 2 & 67 \\
\hline $\begin{array}{l}\text { Adverse events following immunisation (AEF } \\
\text { administration of a vaccine(s). } \\
{ }^{a} \text { Reaction categories were created for the AE } \\
360-3)^{14} \text { as described in Methods section. Th } \\
\text { but included in AEFI records in the Adverse } \\
{ }^{b} \text { Reaction categories like gastrointestinal rel } \\
\text { had eight reports; increased sweating and } p \\
{ }^{c} \text { There were no reports for reaction categori } \\
\text { syndrome and abscess. } \\
{ }^{d} \text { Not shown if neither age nor date of birth } \\
{ }^{\mathrm{e}} \text { AEFI records where only one reaction was } \\
{ }^{f} \text { Includes skin reactions including pruritus, u } \\
\text { (e.g. diarrhoea, vomiting) symptoms and sign } \\
\text { faeces, hematochezia etc. Does not include } \\
\text { gincludes general terms of rash but does no } \\
{ }^{h} \text { Includes lymphadenitis following Bacillus o } \\
\text { Source: Adverse Drug Reactions System dat }\end{array}$ & $\begin{array}{l}\text { are generally rega } \\
\text { of interest listed a } \\
\text { ottom part of the } \\
\text { ig Reactions Syst } \\
\text { d to rotavirus anc } \\
\text { r each had sever } \\
\text { ike acute flaccid } \\
\text { re recorded. } \\
\text { orted. } \\
\text { aria, periorbital o } \\
\text { ut does not inclu } \\
\text { aphylaxis. }{ }^{10} \\
\text { alude rash pruriti } \\
\text { almette and Guér } \\
\text { sherapeutic } C\end{array}$ & $\begin{array}{l}\text { d as } \\
\text { defi } \\
\text { ble st } \\
\text { data } \\
\text { eart r } \\
\text { port } \\
\text { lysis }\end{array}$ & $\begin{array}{l}\text { seriou } \\
\text { in The A } \\
\text { s reacti } \\
\text { e. } \\
\text { rhythm } \\
\text { shing h } \\
\text { tability, }\end{array}$ & $\begin{array}{l}\text { unexp } \\
\text { alian I } \\
\text { rms n } \\
\text { nge ha } \\
\text { hree r } \\
\text { hingiti }\end{array}$ & $\begin{array}{l}\text { I advers } \\
\text { nisation } \\
\text { ed in Th } \\
\text { reports } \\
\text { s and p } \\
\text { itis, os }\end{array}$ & $\begin{array}{l}\text { vents } \\
\text { ndboo } \\
\text { ustralic } \\
\text { ch; tre } \\
\text { titis ha } \\
\text { s, oste }\end{array}$ & $\begin{array}{l}\text { occur } \\
\text { th editi } \\
\text { mmunis } \\
\text { had } 10 \\
\text { ne repc } \\
\text { yelitis, }\end{array}$ & $\begin{array}{l}\text { er the } \\
\text { pp. } 5 \\
\text { ion } \mathrm{Ha} \\
\text { eports, } \\
\text { sis, to }\end{array}$ & $\begin{array}{l}55 \text { and } \\
\text { book }{ }^{10} \\
\text { shema } \\
\text { shock } \\
\text { ormal }\end{array}$ \\
\hline
\end{tabular}

vaccines. Eighty-six percent of cases recorded as 'not fully recovered' had missing information on hospitalisation. Of these, $62 \%$ were reported by health care providers, $18 \%$ by NSW Health and $20 \%$ by members of the public. Information on severity could not be determined for $26 \%$ of records $(n=109) ; 86 \%$ of these were following receipt of influenza vaccines and $56 \%$ of these reports came from members of public with little information provided. Of those without information describing severity, the most commonly reported adverse reactions were: fever (59\%); allergic reactions $(39 \%)$; malaise $(13 \%)$; injection site reaction $(12 \%)$; headache $(11 \%)$; convulsion, nausea and rash (6\% each); myalgia (5\%); and syncope and dizziness (3\% each). 
Table 3. Outcomes of adverse events following immunisation for two age groups ( $<7$ and $\geq 7$ years), NSW, 2010

\begin{tabular}{|c|c|c|c|c|c|c|}
\hline \multirow[t]{3}{*}{ Outcome } & \multicolumn{2}{|c|}{ AEFI records } & \multicolumn{4}{|c|}{ Age group } \\
\hline & \multirow[b]{2}{*}{$n$} & \multirow[b]{2}{*}{$\%^{a}$} & \multicolumn{2}{|c|}{$<7$ years } & \multicolumn{2}{|c|}{$\geq 7$ years } \\
\hline & & & $n$ & $\%^{\mathbf{b}}$ & $n$ & $\%^{\mathrm{b}}$ \\
\hline Non-serious & 214 & 50 & 135 & 63 & 78 & 36 \\
\hline Not recovered at time of report & 64 & 15 & 23 & 36 & 40 & 63 \\
\hline Unknown ${ }^{c}$ & 109 & 26 & 58 & 53 & 47 & 43 \\
\hline Serious: & 37 & 9 & 27 & 73 & 10 & 27 \\
\hline recovered with sequelae & 1 & & 1 & 100 & - & \\
\hline hospital treatment - admission & 32 & & 24 & 75 & 8 & 25 \\
\hline life-threatening event & 4 & & 2 & 50 & 2 & 50 \\
\hline death (maybe drug) & - & & - & - & - & - \\
\hline Total & 424 & 100 & 243 & 57 & 175 & 41 \\
\hline $\begin{array}{l}\text { Adverse events following immunisatiol } \\
\text { administration of a vaccine(s). } \\
\text { a'Percentages relate to the total numbe } \\
\text { bercentages relate to the number of } \\
\text { for children aged less than } 7 \text { years). } \\
\text { 'Unknown' outcome relates to the nur } \\
\text { Source: Adverse Drug Reactions Systen }\end{array}$ & $\begin{array}{l}\text { genera } \\
\text { ecords ( } \\
\text { s with } t \\
\text { FI recor } \\
\text { Therap }\end{array}$ & as any & $\begin{array}{l}\text { unexpe } \\
\text { I4 AEFI } \\
\text { with un }\end{array}$ & $\begin{array}{l}\text { rse eve } \\
\text { th a 'nc } \\
\text { tcome. }\end{array}$ & $\begin{array}{l}\text { ccur aft } \\
\text { 'outco }\end{array}$ & \\
\hline
\end{tabular}

The reactions recorded as 'serious' were: convulsions $(n=9)$, including six febrile convulsions; fever $(n=6)$; hypotonic-hyporesponsive episodes $(n=6)$; diarrhoea/ vomiting $(n=6)$; allergic reactions $(n=5)$; Guillain-Barrè syndrome $(n=3)$; injection site reactions $(n=3)$; and one case each of intussusception, anaphylaxis and Idiopathic Thrombocytopenic Purpura. Other severe reactions not recorded as 'serious' were: convulsions $(n=20)$, including 11 febrile convulsions; hypotonic-hyporesponsive episodes $(n=2)$; and Guillain-Barrè syndrome $(n=1)$.

Of the 29 cases of convulsion, 27 were children aged less than 7 years. The most commonly suspected vaccines were pH1N1 vaccine $(n=18)$ and seasonal influenza vaccine $(n=11)$, either given alone or co-administered with other vaccines.

All the reports of hypotonic-hyporesponsive episodes were from children aged less than 7 years. Seven reports were following administration of hexavalent/pneumococcal and rotavirus vaccines while one case report was following administration of hexavalent and pneumococcal vaccines only.

All four cases of Guillain-Barrè syndrome were in adults aged 65 years and over and following seasonal flu vaccine $\left(\right.$ Fluvax $\left.^{\circledR}\right)($ CSL Biotherapies) with onset within 24 hours of vaccination.

\section{AEFI reports not including influenza vaccines}

There were 150 AEFI records in 2010 which did not include influenza vaccines, either alone or co-administered with other vaccines. Only one $(0.7 \%)$ was reported by a member of the public.

Eleven percent $(n=17)$ of the 150 AEFI records had outcomes defined as 'serious' (i.e. recovery with sequelae, hospitalisation, life-threatening event or death). Serious AEFIs reported included hypotonic-hyporesponsive episodes $(n=6)$, diarrhoea $(n=4)$, allergic reactions $(n=3)$, injection site reactions $(n=2)$, Idiopathic Thrombocytopenic Purpura $(n=1)$ and intussusception $(n=1)$. There were no reports of life-threatening events and all but one of the children coded as 'serious' was admitted to hospital. The report of intussusception followed administration of hexavalent (DTPa-IPV-HepB-Hib), pneumococcal (PCV7) and rotavirus vaccines in an infant and occurred 2 months post-vaccination. However, due to the length of latency, causality is unlikely to be related to the vaccine. The case of Idiopathic Thrombocytopenic Purpura followed administration of varicella vaccine. However, due to an alternate cause (febrile intercurrent viral infection), the causality is less likely to be related to the vaccine. The distribution of more commonly reported AEFIs is listed in Figure 5.

\section{0 seasonal influenza vaccine}

The majority of reports for seasonal influenza vaccine were for Fluvax ${ }^{\circledR}$ (CSL Biotherapies) $(n=101,67 \%)$ while another $20 \%$ did not specify the vaccine brand and were coded only as influenza vaccine. There were 13 adverse event reports following vaccination with Influvac ${ }^{\circledR}$ (Solvay Biosciences) and six with Vaxigrip ${ }^{\circledR}$ (Sanofi Pasteur). All reports following seasonal influenza 


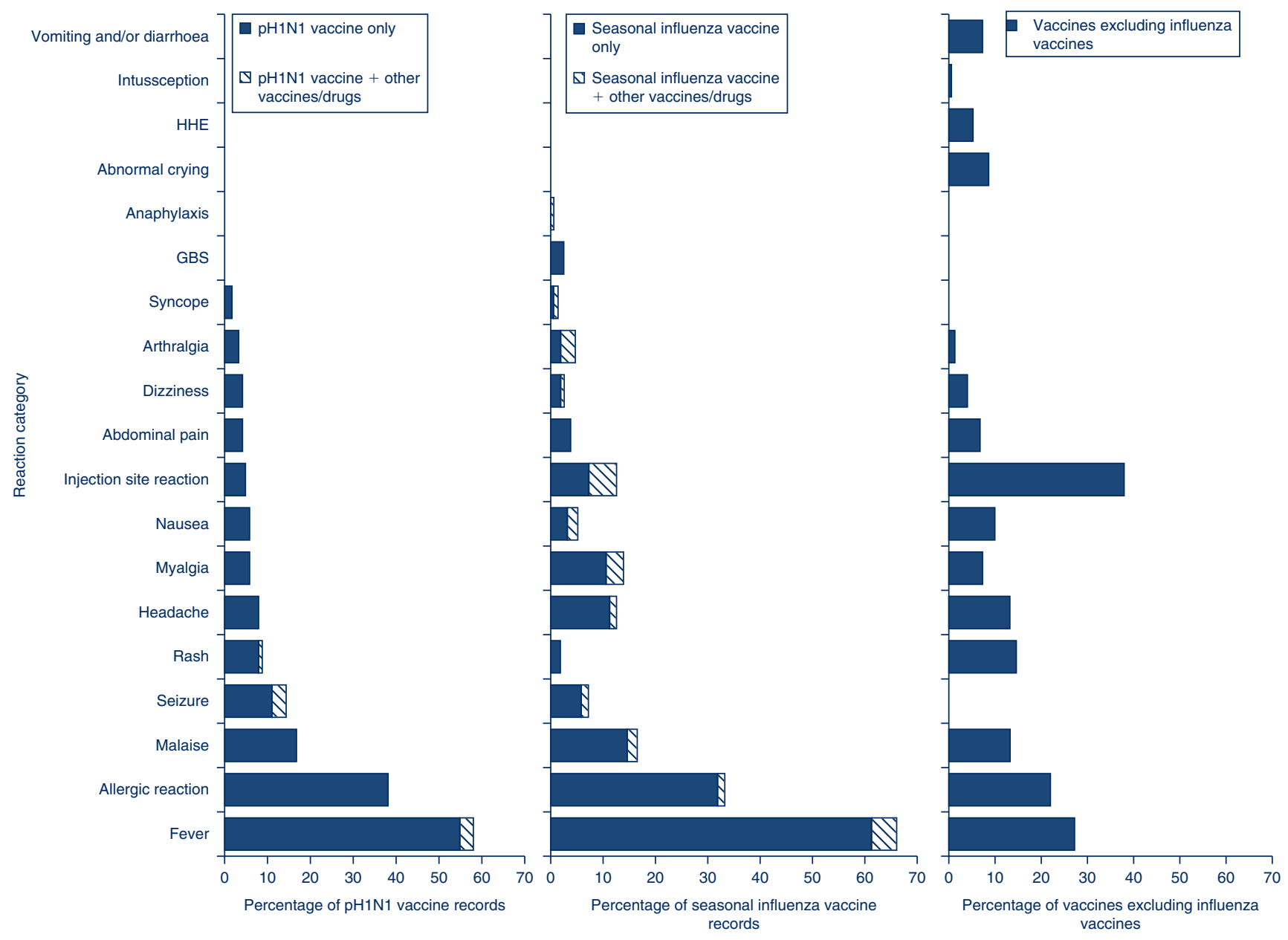

Figure 5. Most frequently reported adverse events following pH1N1 and seasonal influenza immunisation, 2010, by number of vaccines suspected of involvement in the reported adverse event.

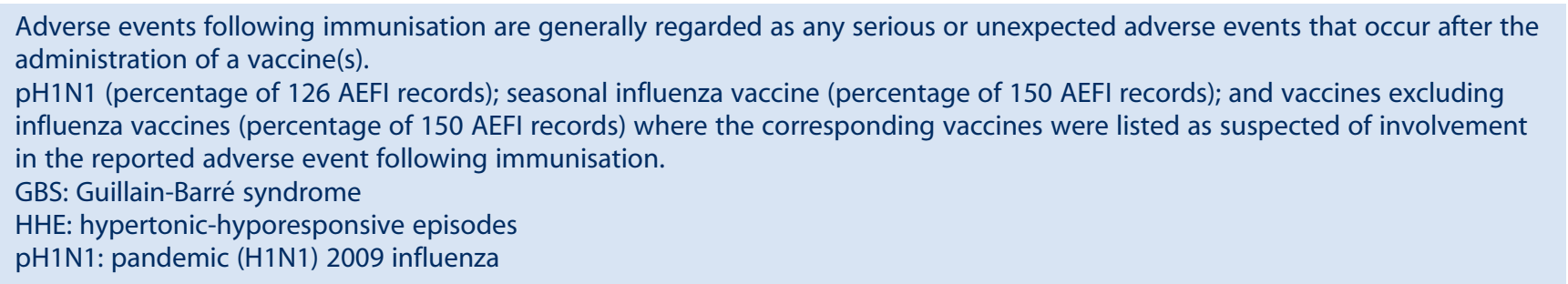

Source: Adverse Drug Reactions System database, Therapeutic Goods Administration.

vaccination in 2010 were received by the TGA on or after the date of announcement of the withdrawal of seasonal influenza vaccine from use in children (23 April 2010).

A large proportion of the AEFIs following seasonal influenza vaccine were reported directly to the TGA by general practitioners and specialists (41\%) and members of the public $(20 \%)$, while $29 \%$ were reported to the TGA by NSW Health. Fifty-nine percent $(n=89)$ of the reports following seasonal influenza vaccine were defined as 'non-serious', 7\% $(n=11)$ were defined as 'serious', $15 \%(n=22)$ were defined as not recovered, and an additional $19 \%$ were not categorised because of the nonavailability of data on hospitalisation and outcome. The distribution of reaction types for seasonal influenza vaccine is presented in Figure 5. The spectrum of reactions for seasonal influenza vaccine was different to that for non-influenza vaccines with a substantially higher proportion of fever ( $66 \%$ compared with $27 \%$ for non-influenza vaccines) and allergic reaction (33\% vs. $22 \%$ ) and a lower proportion of injection site reactions (13\% vs. 38\%). There were 11 reports $(7 \%)$ of convulsions including eight febrile convulsions, four $(3 \%)$ of Guillain-Barrè syndrome and two (1\%) of syncope following seasonal influenza vaccine. A higher proportion of reports following seasonal influenza vaccine came from members of the public $(20 \%$ compared with $0.7 \%$ for non-influenza vaccines).

\section{Monovalent $p H 1 \mathrm{~N} 1$ vaccine}

For pH1N1 pandemic influenza vaccine events, $68 \%$ $(n=86)$ were for children aged 7 years and under. 
Forty-seven percent $(n=59)$ were reported by members of the public directly to the TGA and only $17 \%$ were reported by NSW Health to the TGA. Seven percent of the reports following $\mathrm{pH} 1 \mathrm{~N} 1$ influenza vaccine were coded as serious. The distribution of reaction types for $\mathrm{pH} 1 \mathrm{~N} 1$ influenza vaccine is presented in Figure 5. The spectrum of reactions for the $\mathrm{pH} 1 \mathrm{~N} 1$ influenza vaccine was similar to that for seasonal influenza vaccine, showing higher rates for fever (58\%), allergic reaction (38\%), malaise $(17 \%)$ and convulsion (14\%).

\section{Discussion}

There has been an increase in both the number of AEFI reports and population-based reporting rates in both 2009 and 2010. This is due to the substantial increase in reports in children following vaccination with the two available influenza vaccines: the 2010 seasonal trivalent influenza and pandemic ( $\mathrm{pH} 1 \mathrm{~N} 1)$ influenza vaccines.

The pH1N1 program for adults that commenced in September 2009 resulted in a large peak in reports for that age group in the last quarter of that year, followed by substantially lower levels in adults in 2010. Reports in children peaked in 2010 following the roll-out of vaccination to children aged 6 months to 10 years from December 2009. The safety of the $\mathrm{pH} 1 \mathrm{~N} 1$ vaccine has been examined closely both nationally and internationally. The World Health Organization reports that approximately 30 different $\mathrm{pH} 1 \mathrm{~N} 1$ vaccines have been developed using a range of methods. ${ }^{25}$ All progressed successfully through vaccine trials to licensure, showing satisfactory safety profiles, with the most common reactions being severe to moderate fever $(1.2 \%$; 95\% CI, $0.2 \%-6.6 \%)$ and irritability in infants and younger children following the first dose of $\mathrm{pH} 1 \mathrm{~N} 1$ vaccine. ${ }^{26}$ However, these clinical trials were not large enough to detect rare adverse vaccine reactions which occur with a frequency of less than one in 1000. In general, the safety profile, including that for the Australian vaccine, has been similar to those of other vaccines, with predominantly mild transient events and a small number of serious reactions reported. ${ }^{27}$ In Australia, reports of febrile convulsions following Panvax administration were found to be between 10 and 100 per 100000 doses; this is consistent with the definition of a rare event, and substantially less than that for Fluvax ${ }^{\circledR} \cdot{ }^{28}$ Active surveillance for GuillainBarrè syndrome has resulted in no evidence of an increased incidence, and reports of anaphylaxis are also rare and within expectations. $^{29}$

The large number of reports following the administration of the pH1N1 vaccine may be attributable to the active promotion of reporting by the TGA and may reflect the fact that immunisation providers are more likely to report milder, less serious AEFIs for vaccines they are not familiar with. This tendency to report an AEFI for newer vaccines increases the sensitivity of the system to detect signals of serious, rare or previously unknown events, but also complicates the interpretation of trends.

While seasonal influenza vaccines have been used in Australia for decades, a vaccine safety concern emerged in children in 2010. Epidemiological studies determined that the 2010 seasonal influenza vaccine produced by CSL Biotherapies (Fluvax ${ }^{\circledR}$ and Fluvax junior ${ }^{\circledR}$ ) was associated with a rate of febrile convulsions within 24 hours of administration of 500-700 per 100000 doses, ${ }^{28}$ or between 5 and 20 times higher than in other seasonal influenza vaccines and $\mathrm{pH} 1 \mathrm{~N} 1$ vaccine. Very high rates of fever were also found in a follow-up study: $46 \%$ following administration of Fluvax compared to $16 \%$ following $\mathrm{pH} 1 \mathrm{~N} 1$, and $7 \%$ following Influvac. ${ }^{30}$ The use of the 2010 seasonal trivalent influenza vaccine in children aged under 5 years was suspended in April 2010, ${ }^{31}$ after which reporting of AEFIs from seasonal influenza vaccine declined. The recommendation to resume the use of seasonal influenza vaccine in children aged 6 months to 5 years, using brands other than Fluvax ${ }^{\circledR}$ and Fluvax junior ${ }^{\circledR}$, was subsequently made in August $2010 .^{32}$ This issue was initially detected in Western Australia, where vaccine was provided for a larger proportion of children aged 6 months to 5 years through a state-based influenza vaccination program. In other jurisdictions including NSW, only children with medical risk factors were provided with free vaccine. Therefore, the ability of surveillance systems to detect an AEFI 'signal' was limited in these other jurisdictions. However, when results from these jurisdictions were subsequently combined, analyses found a similar rate of febrile convulsions following Fluvax ${ }^{\circledR}$ compared to that in Western Australia. ${ }^{30}$

Stimulated reporting associated with a new vaccine (pH1N1 influenza vaccine) and a vaccine safety issue (Fluvax) is likely to have resulted in increased reporting of milder AEFIs and for other vaccines. AEFI reporting rates for non-influenza vaccines in children were higher in 2010 compared with 2009. After excluding reports of influenza vaccines, the population-based AEFI reporting rate in children aged less than 7 years was three times lower (2.1 per 100000 population) than the overall reporting rate per 100000 population for 2010 in that age group (5.8). This is consistent with levels of reporting in 2004-2008 after the removal of the 18-month dose of DTPa that resulted in a reduction of injection site reactions. The majority of these $(60 \%)$ were reported by the NSW Department of Health and only $0.7 \%$ were reported by members of the public.

The recent increase in reports from members of the public (seven in 2008 compared with 88 in 2010) indicates a high level of public interest in both the $\mathrm{pH} 1 \mathrm{~N} 1$ and seasonal influenza vaccines. This is likely to be due at least in part to the active promotion of the reporting of events following pH1N1 vaccination directly to the TGA, ${ }^{27}$ as well as the issues mentioned above. 


\section{Conclusion}

There was a $24 \%$ higher rate of AEFIs per 100000 population reported from NSW in 2010 compared with 2008 , and a $6 \%$ decrease compared with 2009 . The high rate in 2010 was attributable to a large number of reports following receipt of the $\mathrm{pH} 1 \mathrm{~N} 1$ and seasonal influenza vaccines in children. A higher proportion of these events were reported directly to the TGA by members of the public following promotion of this for $\mathrm{pH} 1 \mathrm{~N} 1$. The majority of reports were of mild transient events. Increases in reporting following the introduction of a new vaccine $(\mathrm{pH} 1 \mathrm{~N} 1)$ are expected. However, high rates of febrile convulsions and fever following seasonal influenza vaccine, predominantly in Western Australia where the vaccine was offered to all children aged 6 months to 5 years, ultimately resulted in the removal of the indication for the use of Fluvax ${ }^{\circledR}$ and Fluvax junior ${ }^{\circledR}$ in children of that age, nationally. ${ }^{31}$ In NSW, where the influenza vaccine was provided only for children in this age group with medical risk factors, there were eight cases of febrile convulsions. These cases contributed to the finding that febrile convulsion reporting rates following Fluvax ${ }^{\circledR}$ were elevated across Australia.

\section{Acknowledgments}

The National Centre for Immunisation Research and Surveillance is supported by the Department of Health and Ageing, the NSW Department of Health and The Children's Hospital at Westmead.

\section{References}

1. Lawrence G, Boyd I, McIntyre P, Isaacs D. Surveillance of adverse events following immunisation: Australia 2002 to 2003. Commun Dis Intell 2004; 28(3): 324-38.

2. Lawrence G, Boyd I. Surveillance of adverse events following immunisation for children aged less than 7 years, 1 January to 30 June 2004. Commun Dis Intell 2004; 28(4): 490-2.

3. Lawrence G, Boyd I. Supplementary report: surveillance of adverse events following immunisation among children aged less than 7 years in Australia, 1 January to 30 June 2005. Commun Dis Intell 2005; 29(4): 413-6.

4. Lawrence G, Boyd I, McIntyre P, Isaacs D. Annual report: surveillance of adverse events following immunisation in Australia, 2005. Commun Dis Intell 2006; 30(3): 319-33.

5. Lawrence G, Boyd I. Supplementary report: surveillance of adverse events following immunisation among children aged $<7$ years in Australia, 1 January to 30 June 2006. Commun Dis Intell 2006; 30(4): 438-42.

6. Lawrence G, Gold MS, Hill R, Deeks S, Glasswell A, McIntyre PB. Annual report: surveillance of adverse events following immunisation in Australia, 2007. Commun Dis Intell 2008; 32(4): 371-87.

7. Lawrence GL, Boyd I, McIntyre PB, Isaacs D. Annual report: surveillance of adverse events following immunisation in Australia, 2004. Commun Dis Intell 2005; 29(3): 248-62.

8. Lawrence GL, Aratchige PE, Boyd I, McIntyre PB, Gold MS. Annual report on surveillance of adverse events following immunisation in Australia, 2006. Commun Dis Intell 2007; 31(3): 269-82.

9. Lawrence GL, Aratchige PE, Hill R. Supplementary report: surveillance of adverse events following immunisation among children aged less than 7 years in Australia, 1 January to 30 June 2007. Commun Dis Intell 2007; 31(4): 379-82.

10. Lawrence GL, Mahajan D, Roomiani I. Supplementary report: surveillance of adverse events following immunisation among children aged $<7$ years in Australia, 1 January to 30 June 2008. Commun Dis Intell 2009; 33(1): 27-31.

11. Mahajan D, Menzies R, Roomiani I, Lawrence GL. Supplementary report: surveillance of adverse events following immunisation among children aged $<7$ years in Australia, 1 January to 30 June 2009. Commun Dis Intell 2010; 34(1): 49-53.

12. Menzies R, Mahajan D, Gold MS, Roomiani I, McIntyre P, Lawrence G. Annual report: surveillance of adverse events following immunisation in Australia, 2008. Commun Dis Intell 2009; 33(4): 365-81.

13. Victorian State Government, Department of Health. National immunisation program schedule. Available from: http://health. vic.gov.au/immunisation/fact-sheets/factsheets/schedule_ victoria (Cited 1 December 2010.)

14. Australian Government Department of Health and Ageing, Therapeutic Goods Administration. TGA approves vaccine against pandemic (H1N1) 2009 influenza. 18 September 2009. Available from: http://www.tga.gov.au/media/mr2009.htm (Cited 2 December 2010.)

15. National Health and Medical Research Council. The Australian Immunisation Handbook. 8th ed. Canberra: Australian Government Department of Health and Ageing; 2003.

16. National Health and Medical Research Council. The Australian Immunisation Handbook. 9th ed. Canberra: Australian Government Department of Health and Ageing; 2008.

17. Uppsala Monitoring Centre. WHO Collaborating Centre for International Drug Monitoring. 2009. Available from: http://www.who-umc.org/ (Cited 1 February 2009.)

18. Zhou W, Pool V, Iskander JK, English-Bullard R, Ball R, Wise RP et al. Surveillance for safety after immunization: Vaccine Adverse Event Reporting System (VAERS)-United States, 1991-2001. MMWR Surveill Summ 2003; 52(1): 1-24.

19. Brown EG, Wood L, Wood S. The medical dictionary for regulatory activities (MedDRA). Drug Saf 1999; 20(2): 109-17. doi:10.2165/00002018-199920020-00002

20. Bonhoeffer J, Gold MS, Heijbel H, Vermeer P, Blumberg D, Braun $\mathrm{M}$ et al. Hypotonic-hyporesponsive episode (HHE) as an adverse event following immunization: case definition and guidelines for data collection, analysis, and presentation. Vaccine 2004; 22(5-6): 563-8. doi:10.1016/ j.vaccine.2003.09.009

21. Rüggeberg JU, Gold MS, Bayas JM, Blum MD, Bonhoeffer J, Friedlander S et al. Anaphylaxis: case definition and guidelines for data collection, analysis, and presentation of immunization safety data. Vaccine 2007; 25(31): 5675-84. doi:10.1016/ j.vaccine.2007.02.064

22. Australian Bureau of Statistics. 31010DO002_201006 Population by Age and Sex, Australian States and Territories, Jun 2010. Australian Bureau of Statistics; 2010. Released at 11:30 am (Canberra time) 21 December 2010. 
23. Centre for Epidemiology and Research. Summary report on adult health from the NSW Population Health Survey, 2009. Sydney: NSW Department of Health; 2010.

24. Mahajan D, Campbell-Lloyd S, Roomiani I, Menzies R. NSW Annual Adverse Events Following Immunisation Report, 2009. N S W Public Health Bull 2010; 21(9-10): 224-33. doi:10.1071/NB10048

25. World Health Organization. Safety of pandemic A (H1N1) influenza vaccines. Wkly Epidemiol Rec 2010; 85(5): 29-36.

26. Nolan T, McVernon J, Skeljo M, Richmond P, Wadia U, Lambert $\mathrm{S}$ et al. Immunogenicity of a monovalent 2009 influenza A (H1N1) vaccine in infants and children: a randomized trial. JAMA 2010; 303(1): 37-46. doi:10.1001/ jama.2009.1911

27. Australian Government Department of Health and Ageing. Therapeutic Goods Administration, Cook J. Australian experience with non-adjuvant H1N1 vaccine (Panvax and Panvax Junior). Medicines Safety Update No. 4, 2010. Available from: http://www.tga.gov.au/adr/msu/msu1008.htm\#austexper (Cited 30 August 2010.)

28. Australian Government Department of Health and Ageing, Therapeutic Goods Administration. Australian Technical Advisory Group on Immunisation (ATAGI) and Therapeutic Goods Administration (TGA) Joint Working Group Analysis of febrile convulsions following immunisation in children following monovalent pandemic H1N1 vaccine (Panvax/Panvax Junior, CSL). Available from: http://www.tga.gov.au/safety/alerts-medicine-seasonalflu-100928.htm (Cited 30 May 2011.)

29. Australian Government Department of Health and Ageing, Therapeutic Goods Administration. Suspected adverse reactions to Panvax ${ }^{\circledR}$ reported to the TGA. 30 September 2009 to 17 September 2010. Available from: http://www.tga.gov.au/safety/ alerts-medicine-panvax-091120.htm (Cited 30 May 2011.)

30. Australian Government Department of Health and Ageing, Therapeutic Goods Administration. Investigation into febrile reactions in young children following 2010 seasonal trivalent influenza vaccination. Status report as at 2 July 2010 (updated 24 September 2010). Available from: http://www.tga.gov.au/ safety/alerts-medicine-seasonal-flu-100702.htm (Cited 30 May 2011.)

31. Australian Government Department of Health and Ageing, Therapeutic Goods Administration. Departmental Media Releases 23 April 2010. Seasonal Flu Vaccine and young children. Available from: http://www.health.gov.au/internet/ main/publishing.nsf/Content/mr-yr10-dept-dept230410.htm (Cited 30 May 2011.)

32. Australian Government Department of Health and Ageing, Therapeutic Goods Administration. Departmental Media Releases 30 July 2010. Seasonal flu vaccination for young children can be resumed-Updated advice from the Chief Medical Officer. Available from: http://www.health.gov.au/ internet/main/publishing.nsf/Content/mr-yr10-deptdept300710.htm (Cited 30 May 2011.)

\section{New Senior Hospitalist Initiative: a new medical career pathway for NSW Health}

New South Wales (NSW) is developing a new medical career pathway for hospitalists. Hospitalists will provide a range of clinical services and promote coordinated patient care across disciplines. The establishment of the hospitalist role and development of an education program for experienced non-specialist doctors was recommended by the Garling Special Commission of Inquiry into Acute Care Services in NSW public hospitals. The report recognised that "Hospitalists have an important role in coordinating the care of a patient who has needs which cross boundaries of individual specialities".

The hospitalist pathway offers a flexible, interesting and attractive career to non-specialists keen to remain involved in acute patient care, while leading improvements in the coordination of hospital services. The pathway will be supported by the Masters of Clinical Medicine (Leadership and Management) which will focus on the range of skills required for senior hospitalist roles within NSW Health. The Masters, or equivalent, will be a requirement for eligibility for NSW Health Senior Hospitalist positions as an alternative to the Senior Career Medical Officer Grading Committee.

The 2-year part-time Masters, endorsed by NSW Health, will begin in 2012. The program is open to non-specialist doctors with 3 years full-time postgraduate medical experience. It will be accessible statewide through flexible delivery options and will have a substantial workplace component. To support eligible NSW Health doctors to participate in the Masters, the Department will sponsor 15 places in 2012.

Those interested in finding out more about the Senior Hospitalist Initiative, including sponsorship and enrolment information, should check the NSW Health website at: http://www.health.nsw.gov.au/training/hospitalist/

Cathie Hull, Senior Policy Officer, NSW Ministry of Health

Catherine Ellis, Principal Policy Analyst, NSW Ministry of Health 